\section{Entre posse e acesso: compreendendo a extensão do self no consumo colaborativo}

\author{
Between ownership and access: understanding the extension of the self in \\ collaborative consumption
}

Marianny Jessica de Brito Silva ${ }^{a}$

Maria de Lourdes de Azevedo Barbosa ${ }^{\mathrm{a}}$

Marconi Freitas da Costa ${ }^{a}$

Jairo de Pontes Gomes ${ }^{b}$

a Universidade Federal de Pernambuco, Recife, PE, Brasil

- Universidade Federal da Paraíba, João Pessoa, PB, Brasil
Revista Organizações \& Sociedade 2020, 27(93), 333-356

(c) Autor(es) 2020

DOl 10.1590/1984-9270939

ISSN 1984-9230

www.revistaoes.ufba.br

NPGA, Escola de Administração

Universidade Federal da Bahia

Recebido: 25/04/2018

Aprovado: 11/04/2019

\title{
Resumo
}

A pesquisa busca compreender como se dá a extensão do self na prática do consumo colaborativo por meio do sistema de compartilhamento de bicicletas de Pernambuco. 0 estudo é alicerçado em abordagem qualitativa, com dados coletados por observação participante nas plataformas do Bike PE e entrevistas individuais não estruturadas com 24 usuários do projeto. Os dados foram interpretados a partir da aplicação da análise de discurso social-hermenêutica. Verificou-se que a possibilidade de pedalar pelo Bike PE representa uma oportunidade para reafirmar e construir certos elementos identitários ligados especialmente ao social e ao coletivo que estimulam ações conjuntas e/ou interativas. Assim, a identidade na prática colaborativa dos usuários do Bike PE é desenvolvida e estendida a partir do self relacional e do self influenciador e idealista. Identificou-se ainda que alguns usuários são também proprietários de bicicletas, apontando que o consumidor está disposto a experimentar novos modelos de prestação de serviços sem abandonar antigas práticas de consumo, como a aquisição de um bem. Com uma identidade multifacetada, os indivíduos buscam possibilidades de extensão e construção do self por meio do acesso e da posse, sendo a utilização do produto o elemento central na construção e extensão identitária, independentemente de o objeto usado ser próprio ou não.

Palavras-chave: Extensão do Self; Consumo Colaborativo; Posse; Compartilhamento; Bike.

\section{Abstract}

This paper analyzes how the extension of the self in the practice of collaborative consumption in the system of sharing of bicycles of Pernambuco takes place. It has a qualitative approach, collecting the data through participant observation on Bike PE platforms and individual unstructured interviews with 24 project users. Social-hermeneutical discourse analysis was used to analyze the data. The possibility of cycling provided by Bike PE represents the opportunity to reaffirm and build certain identity elements, especially those related to the social and collective aspects that stimulate joint and/or interactive actions. Thus, two elements constitute the development and extension of identity in the collaborative practice of Bike PE users: the relational self and the influencing and idealistic self. Many users were shown to already possess a bicycle, indicating that the consumer is willing to experiment new business models without abandoning previous consumer practices such as the acquisition of a good. With a multifaceted identity, individuals want to increase their possibilities of extension and construction of self through access and possession, and the use of the referred product is a central element in the construction and extension of identity, regardless of whether the object used being their own or not.

Keywords: Extension of the Self; Collaborative Consumption; Possession; Sharing; Bike. 


\section{Introdução}

Os indivíduos vivem em uma cultura em que o consumo é parte de suas identidades (Kizgin, Jamal, \& Richard, 2018). Assim, a atividade de consumir começa e termina com o self (Bagozzi, 2013), sendo este entendido como a maneira como o indivíduo se define, tendo como sinônimos as palavras "identidade" e "autoconceito" (Ruvio \& Belk, 2018).

Os estudos de marketing que discutem a relação destes dois constructos têm auxiliado na compreensão do consumo enquanto prática, que expõe a subjetividade dos indivíduos e auxilia na construção de um projeto identitário em prol de um self coerente (Shankar, Elliott, \& Fitchett, 2009). As posses, particularmente, auxiliam nestas representações identitárias, sendo reconhecidas por Belk (1988) como ferramentas de extensão do indivíduo e, portanto, partes do seu próprio ser. A partir da propriedade, portanto, tem-se o Eu estendido (Belk, 1988), teoria desenvolvida para reconhecer que as pessoas transpassam e expõem seus selves (plural de self, em inglês) por meio daquilo que possuem (Kunchamboo, Lee, \& Brace-Govan, 2017).

A partir das mudanças provocadas pelas inovações tecnológicas, crises econômicas mundiais e preocupações ambientais, surgiram novas configurações de consumo que incentivaram práticas colaborativas, resultando na substituição da propriedade pela possibilidade da experiência do acesso, surgindo, em decorrência desse novo contexto, o consumo colaborativo (Lang \& Armstrong, 2018). As questões de identidade nesse ambiente podem estar sendo pautadas em novos elementos, e a extensão do self parece ocorrer a partir de outras propostas para além da propriedade.

A ideia de alugar algo por um período de tempo em vez de comprar sugere uma mudança de ideologia que passa a incentivar o acesso em detrimento da propriedade. Esta constatação parece destacar a existência de mudanças nos processos de produção social da subjetividade e na criação de novos valores e sensibilidades (Barnes \& Mattsson, 2017). A partir delas, percebe-se que a construção e extensão do Eu pode não estar ligada apenas ao que se entende pelo termo "possuir". Apesar destas constatações, não foram encontrados estudos que buscassem compreender como o Eu é construído e estendido no consumo colaborativo (Hartl, Hofmann, \& Kirchler, 2016); também não se conseguiu acessar pesquisas sobre o entendimento de como estas configurações representam uma passagem do "eu sou o que possuo" para "eu sou o que acesso".

Assim, reconhecendo a necessidade de pesquisas que tragam novas perspectivas para as teorias de marketing e de comportamento do consumidor, este artigo centra sua análise na compreensão da extensão do Eu na prática do consumo colaborativo, tendo o sistema de compartilhamento de bicicletas de Pernambuco, Bike PE, como lócus de pesquisa. Portanto, o objetivo deste estudo foi compreender a extensão da identidade dos usuários do Bike PE neste tipo de prática colaborativa, desenvolvendo uma reflexão acerca da relação entre posse e acesso.

A relevância desta pesquisa reside no avanço do conhecimento sobre a construção e a extensão identitária dos consumidores no que se refere às ações de compra, uso e descarte, contribuindo ao atentar para o self estendido no consumo colaborativo, perspectiva ainda não explorada no campo do comportamento do consumidor. Como uma contribuição prática, a pesquisa pode orientar melhorias em atividades colaborativas e oportunidades de negócio voltadas a esta nova configuração de consumo.

Para o desenvolvimento ordenado do tema proposto, o trabalho está dividido em três seções posteriores a esta, em que são abordados: (1) os conceitos de self e de extended self, (2) o consumo na Era do Acesso e (3) a experiência do consumo colaborativo, envolvendo subseções relacionadas à evolução do conceito e às suas características no Bike PE. Além destas, outra seção descreve o método adotado para 0 desenvolvimento da pesquisa e, em outra ainda, a discussão dos principais resultados é apresentada. Por fim, considerações finais são tecidas à luz dos achados da pesquisa. 


\section{Autoconceito e a compreensão do self}

O reconhecimento da importância simbólica dos produtos por meio das pesquisas na área do comportamento do consumidor durante a década de 1950 incentivou o desenvolvimento de estudos sobre novos temas anteriormente desacreditados e ignorados. Um desses é o "autoconceito" ou "senso de self" (self-concept), construto que diz respeito às crenças de um indivíduo sobre seus próprios atributos e à maneira como ele os avalia (Sirgy, 1982), revelando-se como estrutura organizada da cognição e dos pensamentos que as pessoas têm de si mesmas (Pilarska, 2016).

O self-concept se tornou um construto de interesse dos pesquisadores da área devido às afirmações de Levy (1959) de que o comportamento do consumidor é mais influenciado pelos símbolos encontrados em um produto do que pelas suas características funcionais. De acordo com Grubb e Grathwohl (1967), o comportamento do indivíduo é orientado para a manutenção do autoconceito, e uma das formas de realizá-la é por meio do uso de produtos como símbolos. A partir desta perspectiva, passou-se a explorar este tipo de relação (Dolich, 1969; Liu, Sprott, Spangenberg, Czellar, \& Voss, 2018; Reed II, 2002).

Destaque deve ser dado ao trabalho de Sirgy (1982), que propôs a teoria da congruência entre imagem do produto e autoimagem, baseada na premissa de que o consumidor geralmente busca produtos e marcas que sejam compatíveis com a sua identidade. 0 autoconceito é construído a partir de uma perspectiva multidimensional (Razmus, Jaroszyńska, \& Palęga, 2017) que, de acordo com Sirgy (1982), envolve o self ideal (o que se gostaria de ser), o self real (como o indivíduo se percebe), o self no contexto (como o indivíduo se enxerga em situações distintas) e o self social (como o indivíduo gostaria que os outros lhe enxergassem). De modo geral, segundo Chaplin e John (2005), a teoria da congruência revelou que produtos que transmitem certas imagens podem ativar benefícios similares nas pessoas.

A partir dessa definição sobre self, Belk (1988) desenvolve a teoria do Eu estendido (extended self), sustentando que a chave para a compreensão do que as posses significam seria o reconhecimento de que os indivíduos consideram suas posses como parte de si mesmos. Assim, descreveu o self como o ser e o extended self como as posses na forma da extensão daquilo que o indivíduo é. Partindo-se do princípio do Eu estendido, é possível considerar que as pessoas são, até certo ponto, o que elas possuem (Baumhammer, Silva, \& Costa, 2017). A propriedade, ou pelo menos o senso de propriedade, portanto, surge como elemento central nesta teoria, seja ela uma propriedade individual ou coletiva, permanente ou temporária (Hanley, Baker, Hanley, \& Garland, 2018).

Morgan (1993) reconheceu a necessidade de uma definição holística do self-concept, partindo-se do reconhecimento de que cada visão de self do indivíduo não é formada apenas por uma imagem do Eu atual, mas por uma imagem influenciada pelas lembranças passadas do indivíduo e suas visões de futuro. Por meio desta afirmação, Morgan (1993) sugere a ideia já descrita por Markus e Nurius (1986) dos possible selves nos estudos do comportamento do consumidor. Eles representam o que os indivíduos poderiam se tornar, o que eles gostariam de se tornar e, o mais importante, o que eles têm medo de se tornar (Markus \& Nurius, 1986). Esta última trata-se de uma dimensão adicional do Eu (Mittal, 2015).

Com as mudanças decorrentes da Era Digital, Belk (2013) resolve atualizar o conceito proposto do Eu estendido. Segundo o autor, as possibilidades de extensão do Eu nunca foram tão amplas, resultando em cinco mudanças cruciais no construto em questão: (1) desmaterialização de muitas posses; (2) reincorporação dos indivíduos em fotos, avatares e vídeos; (3) partilha e geração do Eu revelado, dando oportunidades para os indivíduos apresentarem seus selves de maneiras muito mais simples do que na era sem tecnologias digitais - ademais, as coisas que são de propriedade conjunta, por meio da partilha on-line, aumentam o senso de comunidade imaginada e criam sentimentos de identidade grupal que agregam o senso do Eu, uma vez que o self é fundamentalmente relacional (Andersen \& Chen, 2002; Markos, Labrecque, \& Milne, 2018); (4) coconstrução do self - os comentários e demais interações on-line auxiliam os indivíduos a construir suas identidades com auxílio dos demais envolvidos na rede, por meio de um feedback instantâneo, podendo 
auxiliar o senso de afirmação ou de modificação do Eu; e (5) memória distribuída, pois, no mundo digital, dispositivos e tecnologias auxiliam na recordação e arquivamento de nossas memórias, que reforçam o senso do Eu por meio do passado (Belk, 2013).

A nova teoria do Eu estendido considera o self muito mais ativamente gerenciado, construído em conjunto, interativo, abertamente desinibido, confessional, multiplamente manifestado e influenciado pelo que os indivíduos e seus avatares fazem on-line (Belk, 2013). O Quadro 1 visa elucidar a discussão aqui lançada sobre a definição de self e self estendido.

Quadro 1 - Definição do self e do self estendido

\begin{tabular}{|l|l|l|}
\hline \multicolumn{1}{|c|}{ Construtos } & \multicolumn{1}{|c|}{ Definição } & \multicolumn{1}{|c|}{ Referências } \\
\hline \multirow{5}{*}{ Self } & $\begin{array}{l}\text { Sinônimo de identidade ou autoconceito, o self é entendido como a } \\
\text { maneira com que o indivíduo se define, sendo composto por percepções } \\
\text { presentes, passadas e futuras. Apresenta diversas dimensões, tais } \\
\text { como o self real (o que sou) e o self ideal (como gostaria de ser). }\end{array}$ & $\begin{array}{l}\text { Sirgy (1982) } \\
\text { Belk (1988) } \\
\text { Pilarska (2016) } \\
\text { Liu et al. (2018) }\end{array}$ \\
\hline \multirow{3}{*}{ Self estendido } & $\begin{array}{l}\text { Os indivíduos consideram suas posses como partes de si mesmos. } \\
\text { Assim, entende-se como self estendido a identidade do indivíduo } \\
\text { transpassada e exposta pelo bem que possui, dotado de significados } \\
\text { que definem o seu possuidor. }\end{array}$ & $\begin{array}{l}\text { Bhuvia (2005) } \\
\text { Gjersoe, Newman, Chituc, } \\
\text { \& Hood (2014) } \\
\text { Hanley et al. (2018) }\end{array}$ \\
\hline
\end{tabular}

Fonte: Elaborado pelos autores.

\section{0 consumo na Era do Acesso}

"Era do Acesso" é uma expressão cunhada por Rifkin (2000) para descrever o novo modelo econômico, social e humano da sociedade capitalista atual pautado na transição da ideia de posse da propriedade física para o acesso de bens e serviços alcançados graças às possibilidades digitais geradoras de transformações mercadológicas e culturais. Nessa Era, a propriedade, ainda que existente, torna-se um modelo antiquado, incapaz de oferecer a flexibilidade necessária diante das rápidas variações nos mercados, sendo substituída pelo conceito de acesso, que orienta a possibilidade de uso e que tem como força motriz o capital intelectual.

Os consumidores, segundo Rifkin (2000), também já começam a trocar a propriedade pelo acesso, que passa a ser compreendido como um modo de consumo (Bardhi \& Eckhardt, 2012). Nessa perspectiva, os indivíduos buscam acessar os bens e preferem pagar pelas experiências de acesso temporário a estes (Bardhi \& Eckhardt, 2012; Silva \& Barbosa, 2018), demarcando estratégias do usar em vez do possuir (Leismann, Schmitt, Rohn, \& Baedeker, 2013). 0 acesso tem sido estigmatizado historicamente, sendo compreendido como um modo inferior de consumo que limita a liberdade individual e que é realizado simplesmente por uma motivação de ordem financeira (Cheshire, Walters, \& Rosenblatt, 2010; Silva \& Barbosa, 2016). Com o advento das tecnologias, no entanto, o consumo baseado no acesso tem se tornado um fenômeno importante enquanto prática mais flexível e adaptável (Vouga, 2017), pois emerge como alternativa para gerenciar as mudanças (Bardhi \& Eckhardt, 2012).

Nesse sentido, o consumo baseado no acesso pode ser definido como "transações que podem ser mediadas pelo mercado em que nenhuma transferência de propriedade toma lugar" (Bardhi \& Eckhardt, 2012, p. 881). É, portanto, uma prática em que o consumidor adquire tempo, mas não a posse do bem, podendo o mercado mediar as transações, ganhando determinada quantia pelo uso do objeto (Correa et al., 2019), estabelecendo-se distinções entre posse e acesso. Bardhi e Eckhardt (2012) apontam duas principais diferenças que são importantes como base de reflexão para o presente estudo: (1) a natureza da relação self-objeto e (2) as regras que regulam este relacionamento. Em relação à primeira diferença, reconhece-se que a posse é permanente ou está por um longo tempo em interação com o seu dono, já o acesso é um consumo circunstancial e temporal (Lang \& Armstrong, 2018). 
No que diz respeito à segunda diferença, compreende-se que, na propriedade, o indivíduo tem total direito do bem (Silva \& Barbosa, 2018). Esta única característica traz liberdade e responsabilidade para o detentor do item; ele escolhe o momento, a duração de uso e quem pode ou não utilizar seu objeto (Möhlmann, 2015). Já o acesso não tem esta característica e, portanto, a natureza e o gerenciamento dos relacionamentos pessoa-objeto e pessoa-pessoa não estão muito bem estabelecidos (Lamberton, 2016). Neste consumo baseado no acesso se encontram muitas práticas, entre as quais o consumo colaborativo (Belk, 2014b). Esse tipo de experiência é abordado no próximo tópico.

\section{A experiência do consumo colaborativo}

O consumo colaborativo surge impulsionado pela Era do Acesso e por outros fatores que auxiliaram a adoção dessa prática pela sociedade (Hamari, Sjöklint, \& Ukkonen, 2016), tais como: sobrecarga econômica e crise financeira global, escassez de recursos e uso das tecnologias inteligentes e redes sociais peer-to-peer (Gansky, 2010). Ainda como elemento de motivação à adoção de práticas colaborativas, tem-se o movimento de reurbanização, caracterizado pela vivência de indivíduos em casas compactas e menores, impossibilitando a propriedade de muitos objetos (Bardhi \& Eckhardt, 2012; Lang \& Armstrong, 2018).

Desenvolvendo-se nesse cenário, o consumo colaborativo trouxe implicações para a forma como as pessoas consomem, reconhecendo a importância da experiência para além do próprio bem (Botsman \& Rogers, 2011). A experiência é essencialmente emocional e pessoal, envolvendo fatores como interpretação pessoal de uma situação a partir de um contexto histórico cultural, de momentos anteriores e de traços da personalidade (Pullman \& Gross, 2003). Compreender o consumo colaborativo como uma experiência é reiterar que o foco do estudo dessa prática está no indivíduo que a consome e não nos atributos daquilo que é consumido (Möhlmann, 2015). Esta compreensão fortalece a adoção do acesso em detrimento da propriedade. Trata-se, portanto, de uma experiência do acesso, do compartilhamento.

Assim, as práticas colaborativas convergem para um modo de consumo que vai de encontro à possessividade, movidas por valores que incentivam o compartilhamento e que podem contribuir para a sustentabilidade na perspectiva ambiental, diminuindo os desperdícios e aumentando a vida útil dos bens (Markus \& Orsi, 2016), colaborando para uma menor degradação do meio ambiente, além da redução da produção de novos itens (Botsman \& Rogers, 2011), ainda que estes não sejam seus objetivos principais.

Evolução do conceito do consumo colaborativo

O termo "consumo colaborativo" se originou a partir do estudo de Felson e Spaeth (1978), sendo descrito como determinados acontecimentos em que as pessoas consomem bens e serviços econômicos de maneira engajada e conjunta. Entretanto, apenas nos anos 2000 o consumo colaborativo se tornou mais conhecido, sendo redefinido a partir da tecnologia e de comunidades entre pares (Piscicelli, Cooper, \& Fisher, 2015), facilitando a conexão e comunicação entre indivíduos, empresas e grupos de interesse (Lamberton, 2016).

Em 2007, o termo em análise já fazia parte do vocabulário mercadológico, sendo visto por Algar (2007) como uma prática cada vez mais frequente na qual consumidores colaboram on-line para trocas de bens e serviços. É em 2011, entretanto, que o termo se torna mais conhecido no meio acadêmico a partir dos estudos de Botsman e Rogers (2011), autores responsáveis pelo desenvolvimento da nova conceituação do fenômeno.

Para esses autores, o consumo colaborativo passou a ser descrito como uma maneira de atender necessidades e desejos do consumidor, com pouco ônus, prezando por atividades sustentáveis e atraentes, tais como a partilha, os empréstimos comerciais, os aluguéis e as trocas, geralmente ocorridos ou organizados em plataformas virtuais (Benoit, Baker, Bolton, Gruber, \& Kandampully, 2017; Lamberton, 2016). Nesta perspectiva, 
Botsman e Rogers (2011) dividiram tais atividades em três grupos: (1) os sistemas de serviços de produtos (SSP), definidos como uma forma de consumo em que determinado produto é utilizado sem a necessidade de sua aquisição; (2) os mercados de redistribuição, que se referem à transferência de propriedade por ter como atividades as trocas e doações de mercadorias usadas; e (3) os estilos de vida colaborativos, que consistem no compartilhamento e troca de ativos menos tangíveis como tempo, espaço, habilidades e dinheiro.

A partir das tipologias sugeridas por Botsman e Rogers (2011), Freitas, Petrini e Silveira (2016) analisaram 72 sites de diferentes manifestações de consumo colaborativo, classificando-os de acordo com o modelo de compartilhamento, a atividade desenvolvida e a presença de transação monetária. A partir desse mapeamento, foram identificadas atividades denominadas (1) novas oportunidades econômicas, que exigem transações financeiras e utilizam plataformas digitais interferentes no processo de consumo (ex.: Zipcar e Airbnb) e (2) consumo de intenção ideológica, em que não ocorre transação monetária, bem como a plataforma digital não interfere no processo, tendo papel de ferramenta de comunicação, intermediando o contato entre as partes interessadas (ex.: Estante Virtual, Couchsurfing). Nesse sentido, o que se verifica é que esses aspectos apresentados revelam que a prática colaborativa impulsiona novos modelos de negócio e a reformulação de práticas mercadológicas existentes, orientando novas formas de consumir, já que os adeptos do consumo colaborativo parecem estar em busca de outras maneiras de comprar e de viver (Silva \& Barbosa, 2018), modificando alguns valores como, por exemplo, o consumo de novos bens de forma exacerbada.

Ainda segundo Botsman e Rogers (2011), independentemente da classificação do consumo colaborativo, todas as atividades nele desenvolvidas compartilham de forma mais ou menos evidente quatro princípios centrais: (1) a massa crítica, em que se tem a compreensão do impulso suficiente para funcionamento do sistema de modo autossustentável (Scaraboto, 2015); (2) a capacidade ociosa, que reforça a necessidade da utilidade do bem e não de sua posse; (3) a crença no bem comum, expressa na consciência de que a prática da colaboração pode ser útil para todos (Vaquero \& Calle, 2013); e (4) a confiança entre estranhos, necessária em maior ou menor grau a partir das transações econômicas e relacionamentos desenvolvidos no exercício dessa prática colaborativa (Santoso \& Erdaka, 2015).

As definições de consumo colaborativo até então descritas são criticadas por Belk (2014b) por suas amplitudes, considerando que estas envolvem muitas atividades, gerando desordens e questionamentos que merecem atenção e reflexão. Assim, o autor desenvolve uma nova conceituação para o consumo colaborativo, descrevendo-o como um subconjunto do consumo baseado no acesso, com consumidores coordenando a aquisição ou distribuição de um recurso por uma pequena quantia ou outra compensação. 0 escambo, a troca e o trato, desde que não envolvam uma transferência permanente de propriedade, são vistos como atividades incluídas nesta configuração de consumo, a partir da definição do autor, excluindo-se, entretanto, a partilha, em que não há uma compensação envolvida, e o gift-giving, pois ocorre uma transferência permanente de propriedade.

Para Belk (2014b), os indivíduos querem ter acesso temporário aos bens em substituição à necessidade de comprá-los e possuí-los (Zamani, Sandin, \& Peters, 2017). Nesta perspectiva, a atividade colaborativa do consumo parte do princípio da desmaterialização, gerando compartilhamento em grande escala sem diminuir a satisfação do locatário individual (Martin \& Upham, 2016). Petrini, Freitas e Silveira (2017), inclusive, consideram o consumo colaborativo como um subconjunto da economia de compartilhamento, caracterizando-o como forma de consumo que orienta uma ação coletiva que estimula "a criação de conexões entre os aspectos indivíduo-privado e o coletivo-público do consumo" (p. 47).

Visando refletir sobre as definições de consumo colaborativo, Silva e Barbosa (2016) desenvolveram um trabalho teórico que aponta as características centrais desse tipo de atividade. Primeiramente, por envolver o termo "colaboração", inclui

trocas e compartilhamento entre os sujeitos envolvidos, por meio de uma interação pautada em boa comunicação, levando aos indivíduos o poder de alcançar coletivamente os resultados esperados. Assim, quando a expressão consumo colaborativo é posta, pressupõe-se um 
consumo construído a partir da interação de consumidores, podendo estes também estar em posição de fornecedores, empenhados no alcance do atendimento de suas necessidades de forma conjunta. Tal afirmação não implica a não existência do mercado como mediador deste consumo. Mas, havendo tal mediação, precisa existir também a colaboração entre consumidores para que a experiência em questão de fato ocorra. (p. 49)

Ademais, tal consumo é organizado e/ou realizado em plataformas digitais, o que destaca a influência da Era Digital em seu desenvolvimento (Santoso \& Erdaka, 2015). A questão financeira também deve ser considerada, uma vez que o consumo colaborativo tem como um de seus objetivos minorar alguns problemas de ordem social. Nesse sentido, as atividades colaborativas se caracterizam por terem um baixo custo financeiro (Silva \& Barbosa, 2016). Assim, as particularidades do consumo colaborativo aqui adotadas partem do trabalho de Silva e Barbosa (2016), apoiado nas contribuições de Botsman e Rogers (2011) e Belk (2014b), e estão condensadas no Quadro 2, a seguir.

Quadro 2 - Características do consumo colaborativo

\begin{tabular}{|l|}
\hline \multicolumn{1}{|c|}{ Consumo realizado ou organizado em plataformas virtuais } \\
\hline $\begin{array}{l}\text { É caracterizado pela possibilidade de acesso (disponibilidade de uso) a bens e serviços } \\
\text { por meio da colaboração entre consumidores }\end{array}$ \\
\hline Práticas que maximizam a utilidade do bem \\
\hline Ocorre mediante uma pequena quantia paga ou outra compensação \\
\hline Pode ser organizado por consumidores ou mediado pelo mercado \\
\hline Sustentabilidade
\end{tabular}

Fonte: Adaptado de Silva e Barbosa (2016, p. 50).

Assim, baseando-se no artigo de Silva e Barbosa (2016), propõe-se que o consumo colaborativo é uma experiência desenvolvida a partir das possibilidades surgidas na Era Digital, que gerou colaboração entre consumidores, destacando o elemento coletivo envolvido nesse modo de consumo (Petrini et al., 2017), podendo ser o mercado o mediador da atividade. 0 acesso aos bens e serviços se dá por uma pequena quantia ou outra forma de compensação, apresentando como ideias norteadoras a maximização da utilidade do bem e a sustentabilidade.

\section{0 consumo colaborativo na prática - projeto Bike PE}

Entre as atividades de consumo descritas como colaborativas destaca-se o compartilhamento de bicicletas. Como panorama geral, verifica-se que essa prática é comum em países da Europa e nos Estados Unidos e vem se tornando, ano a ano, mais popular no Brasil, a exemplo do projeto Bike PE, o lócus deste estudo. O projeto Bike PE foi criado em 2013, resultado de uma parceria entre o governo estadual de Pernambuco, as prefeituras de Olinda, Jaboatão dos Guararapes e Recife e o Banco Itaú, sendo operacionalizado atualmente pela empresa Tembici, (Bike PE, 2017). Verifica-se, portanto, que esta é uma parceria entre órgãos públicos e empresas privadas, reconhecendo-se que é uma atividade mediada pelo mercado.

Visando oferecer aos indivíduos uma alternativa de transporte sustentável de pequeno percurso e a baixo custo, o Bike PE dispõe de estações inteligentes, sustentadas por energia solar, conectadas a uma central de operações via wireless. Os usuários cadastrados em um banco de dados podem retirar, utilizar e devolver uma bicicleta entre as diversas estações (Bike PE, 2017). O que se verifica, neste caso, é a confirmação da possibilidade de acesso a um bem em substituição à compra/propriedade da bicicleta (Lang \& Armstrong, 2018). 
Para a adesão ao Projeto, os indivíduos devem se cadastrar pelo site do Bike PE e comprar um passe mensal no valor de $\mathrm{R} \$ 10,00$ ou um passe diário no valor de $\mathrm{R} \$ 5,00$, sendo este último disponível diretamente na estação. Há também a possibilidade de pagar a taxa de acesso às bicicletas por meio do bilhete VEM, usado para viagens em transportes públicos urbanos, como ônibus (Bike PE, 2017). A pequena quantia paga para acesso às bicicletas do projeto mostra-se condizente com as características de uma prática de consumo colaborativa (Belk, 2014b; Correa et al., 2019; Silva \& Barbosa, 2016).

Segundo o termo de adesão, que deve ser aceito pelos usuários do projeto Bike PE (2017), o sistema de compartilhamento de bicicletas funciona 24 horas por dia, e os usuários podem realizar viagens gratuitas de até 60 minutos diariamente; após este tempo, eles devem devolver a bicicleta e, depois de 15 minutos, podem retirar a mesma ou outra. A partir do aplicativo, baixado gratuitamente em qualquer smartphone, os membros do Bike PE podem consultar a situação das plataformas (em operação ou off-line), o número de bicicletas disponíveis na estação desejada e as possíveis vagas nas plataformas para devolução (Bike PE, 2017).

A utilização de tecnologias digitais está presente em todas as etapas do projeto, reforçando sua importância no desenvolvimento de novas formas de consumo, o que facilita a conexão e comunicação nas atividades de acesso (Gansky, 2010; Lamberton, 2016; Piscicelli et al., 2015). Por meio do aplicativo, é possível gerenciar qual plataforma será acessada e qual bicicleta será utilizada. As próprias plataformas em que as bicicletas estão contam com um sistema complexo de tecnologia coordenada por sistema wireless. O projeto Bike PE é caracterizado como um sistema de compartilhamento que visa beneficiar usuários e sociedade, atuando em 2018 com planos de pagamento diferenciados que envolvem o valor de $\mathrm{R} \$ 160,00$ para assinatura por um ano, e com maior flexibilidade de uso das bicicletas, que podem ser utilizadas durante 60 minutos em dias de semana e 120 nos fins de semana (Bike PE, 2018), realidade ainda não existente durante a coleta de dados da pesquisa.

Se observarmos as classificações de consumo colaborativo propostas por Botsman e Rogers (2011), podemos identificar que a forma praticada no Bike PE seria incluída na tipologia do SSP, que possibilita o uso do bem sem a sua aquisição. Ademais, baseando-se na classificação de Freitas et al. (2016), tal prática de compartilhamento de bicicletas estaria inserida na tipologia de novas oportunidades econômicas, em que há uma transação financeira e se utilizam as plataformas digitais para concretização do processo de compartilhamento.

\section{Método da pesquisa}

O pressuposto ontológico de que a realidade é construída socialmente e subjetivamente, em conjunto com a visão epistemológica de que a realidade deve ser compreendida a partir das percepções dos indivíduos que a constroem, levou à adoção de um caminho de pesquisa qualitativo. A importância dessa metodologia de pesquisa é reforçada pelo entendimento de que a presente investigação está centrada em um fenômeno compreendido a partir de uma experiência (Caelli, Ray, \& Mill, 2003), resultado das significações desenvolvidas pelo indivíduo que dela participa (Merriam, 2002).

Para tanto, utilizou-se como técnicas de coleta de dados a observação direta estruturada participante e a entrevista individual não estruturada. A finalidade da observação derivou da necessidade de acompanhar os usuários do projeto de compartilhamento de bicicletas acessando esta prática, de modo a compreender o contexto no qual este consumo se realiza. Além disso, permitiu contato com os possíveis entrevistados, viabilizando a marcação de algumas entrevistas com usuários do sistema. Assim, a observação auxiliou na familiarização com o campo de pesquisa (Sampieri, Collado, \& Lucio, 2006) e na obtenção de contatos para possíveis entrevistas sobre o projeto. As observações foram realizadas em 13 das 80 estações espalhadas por Recife, Jaboatão dos Guararapes e Olinda. Entretanto, durante o tempo despendido em cada uma delas, 5 plataformas não foram acessadas por nenhum consumidor, impossibilitando a atividade de coleta. Assim, essa prática de pesquisa foi aplicada em 9 estações do Bike PE. 
As plataformas foram escolhidas devido às suas localizações: próximas de universidades e colégios (estações 62 e 80), de centros de comércio e shoppings da cidade (estações 06, 20, 26, 34, 35, 76 e 77), de ambientes propícios para lazer e para a prática de exercícios físicos, além da proximidade a pontos turísticos (estações 03, 06, 20, 57, 63 e 80). 0 tempo despendido em cada uma delas dependeu da movimentação dos usuários, variando de 20 a 160 minutos, e totalizaram-se 44 usuários observados nas plataformas analisadas.

Posteriormente, foram realizadas entrevistas com 24 informantes. Os critérios utilizados para que o indivíduo pudesse participar da pesquisa foram: (1) ser usuário do projeto Bike PE e (2) utilizar as bicicletas compartilhadas pelo menos uma vez por semana, caracterizando a adesão efetiva do cliente ao sistema. Estas entrevistas foram individuais e não estruturadas, permitindo que os entrevistados respondessem perguntas "dentro de sua própria estrutura de referências" (May, 2004, p. 149). Um roteiro foi desenvolvido para auxiliar no desenvolvimento da conversação (Flick, 2004), incluindo tópicos que tratassem de aspectos relacionados à experiência no Bike PE e à identidade dos entrevistados.

Logo após a finalização das entrevistas, foi realizada uma análise preliminar até o ponto em que foi constatado que as informações obtidas começavam a se repetir, considerando-se encerrada a coleta de dados, ratificado o critério da saturação (Silverman, 2010). A partir da entrevista 19, tal critério já foi evidenciado, realizando-se ainda mais 5 entrevistas. Elas foram gravadas por aparelho digital com a devida autorização dos participantes, tendo duração entre 14 minutos e 54 minutos e 14 segundos, e, posteriormente, foram transcritas.

Para análise dos dados foi adotada a análise de discurso na perspectiva social-hermenêutica, também chamada de análise sociológica do discurso, que é uma análise contextual, na qual os argumentos tomam sentido na relação com os autores que os enunciam, em que o aspecto pragmático é considerado, ou seja, aquilo que extrapola a fala (contexto) são fontes de compreensão do discurso (Godoi, 2010). A partir desse método analítico, Mattos (2005) desenvolveu a análise semântica-pragmática da conversação. Esse tipo de análise de discurso consiste na interpretação do significado temático da conversação e no significado da ação durante a entrevista, explorando todo o contexto no qual esta se desenvolve, extrapolando o que foi dito pelo entrevistado e levando em consideração o efeito da presença e das situações criadas pelo entrevistador sobre a expressão do entrevistado. Para tanto, a análise se desenvolveu em cinco fases distintas, conforme exposto no Quadro 3.

Quadro 3 - Fases da análise

\begin{tabular}{|l|l|}
\hline \multicolumn{1}{|c|}{ Fase } & \multicolumn{1}{c|}{ Definição } \\
\hline $1-$ Recuperação & $\begin{array}{l}\text { Recuperação dos momentos das entrevistas, transcrevendo-as após ouvir as gravações de forma atenta, } \\
\text { fazendo anotações preliminares a respeito dos significados que surgem em alguns momentos. }\end{array}$ \\
\hline $\begin{array}{l}2-\text { Análise } \\
\text { do significado } \\
\text { pragmático da } \\
\text { conversação }\end{array}$ & $\begin{array}{l}\text { Leitura da transcrição realizando anotações ao lado do texto, buscando responder as seguintes perguntas: o } \\
\text { que foi acontecendo ao longo da entrevista? Como foi se desenvolvendo o assunto? Quais foram os pontos } \\
\text { altos e momentos de ausência do entrevistado? Em seguida, foi realizada uma segunda leitura, a fim de fazer } \\
\text { surgir o significado nuclear da resposta (ou seja, o que foi realmente dito); os significados incidentes (algo mais } \\
\text { que pode ser extraído da resposta); e os significados de contexto (suposições implícitas a respeito do contexto } \\
\text { relevantes ao tópico). Por fim, realizou-se a revisão com intuito de melhorar a qualidade do material. }\end{array}$ \\
\hline $3-$ Validação & $\begin{array}{l}\text { Validou-se o significado nuclear das respostas dos entrevistados por meio da afirmação realizada pelo } \\
\text { próprio informante em seu aspecto semântico. }\end{array}$ \\
\hline $\begin{array}{l}4-\text { Montagem da } \\
\text { consolidação das } \\
\text { falas }\end{array}$ & $\begin{array}{l}\text { Transferiu-se para uma planilha eletrônica as respostas separadas da entrevista, o significado nuclear, o } \\
\text { significado incidente e de contexto. Como não existiram perguntas pré-estabelecidas, as informações de } \\
\text { cada participante foram alocadas de acordo com as temáticas propostas nos tópicos, subtópicos e pela } \\
\text { proximidade das perguntas que surgiram durante cada conversação. }\end{array}$ \\
\hline $\begin{array}{l}5-\text { Análise de } \\
\text { conjuntos }\end{array}$ & $\begin{array}{l}\text { A partir da visualização dos fatos e evidências relativa a cada entrevistado, a cada pergunta e a cada } \\
\text { entrevista, refletiu-se sobre todo o conjunto das entrevistas, destacando as diferenças e semelhanças obtidas } \\
\text { nas falas dos informantes e em seus significados. }\end{array}$ \\
\hline
\end{tabular}


Durante esse processo, os tópicos incluídos previamente no roteiro orientaram a análise e, a partir das falas dos entrevistados, foram estabelecidas categorias terciárias, secundárias e primárias de investigação. As terciárias foram tecnologia, identidade, valores e experiência no Bike PE. Todas contribuíram para o desenvolvimento da categoria secundária de análise, acesso vs. posse, até a categoria primária, a extensão do self na prática colaborativa em questão (Quadro 4).

Quadro 4 - Tópicos e categorias de análise

\begin{tabular}{|c|c|c|c|}
\hline \multirow{2}{*}{ Tópicos do roteiro } & \multicolumn{3}{|c|}{ Categorias de análise } \\
\hline & Terciárias & Secundária & Primária \\
\hline $\begin{array}{l}\text { Aspectos identitários e de consumo } \\
\text { (1) Definição de si mesmo - o eu que se tem, } \\
\text { o que se quer ser e o que não se quer ser } \\
\text { (2) O consumo durante a vida } \\
\text { (3) A relação com as tecnologias }\end{array}$ & $\begin{array}{l}\text { Identidade e } \\
\text { tecnologias }\end{array}$ & \multirow{3}{*}{ Posse vs. acesso } & \multirow{3}{*}{$\begin{array}{l}\text { A extensão do } \\
\text { self na prática } \\
\text { colaborativa }\end{array}$} \\
\hline $\begin{array}{l}\text { Bike PE } \\
\text { (4) Adesão ao projeto Bike PE } \\
\text { (5) Acesso às bicicletas } \\
\text { (6) Outras práticas colaborativas envolvidas } \\
\text { (7) Relação com outros usuários }\end{array}$ & $\begin{array}{l}\text { Experiência no Bike } \\
\text { PE e no consumo } \\
\text { colaborativo }\end{array}$ & & \\
\hline $\begin{array}{l}\text { Valores e crenças } \\
\text { (8) Ensinamentos ao longo da trajetória de vida } \\
\text { (9) Aspectos de cidadania } \\
\text { (10) Aspectos de sustentabilidade e Saúde } \\
\text { (11) Motivos de adoção e continuidade no Projeto }\end{array}$ & Motivações e valores & & \\
\hline
\end{tabular}

Fonte: Elaborado pelos autores.

Na seção seguinte, a análise de resultados é apresentada a partir das categorias estabelecidas.

\section{Análise dos resultados}

Antes de seguir para a análise dos resultados, fazem-se necessárias algumas considerações acerca dos informantes da pesquisa. Eles apresentaram diferentes tempos de adesão ao projeto, variando de um mês, representando os clientes novos, até usuários presentes desde o início da implantação do projeto Bike PE, em 2013 ("Pernambuco implanta", 2013). A frequência de uso das bicicletas do compartilhamento de Recife também variou entre os entrevistados. Ela pode ser de uma vez por semana, aos domingos por exemplo, até uso cotidiano e diário (segunda a segunda).

Outra diferença observada entre os consumidores do projeto foi a finalidade com que usam a bicicleta. Há usuários que acessam o Bike PE com a finalidade da prática de lazer, outros atrelam a diversão com a preocupação à saúde. Existem usuários que utilizam as bicicletas do projeto com o intuito de dispor de um meio de transporte, estando alguns deles preocupados em melhorar a sua qualidade de vida por meio do exercício físico praticado durante os percursos realizados. A partir das entrevistas com 24 usuários do Bike PE, verificou-se que as finalidades de utilização das bicicletas do sistema podem ser agrupadas em três categorias: lazer, locomoção e vida saudável. Para melhor ilustração, apresenta-se na Figura 1, a seguir, a quantidade de usuários entrevistados divididos entre essas categorias estabelecidas. 


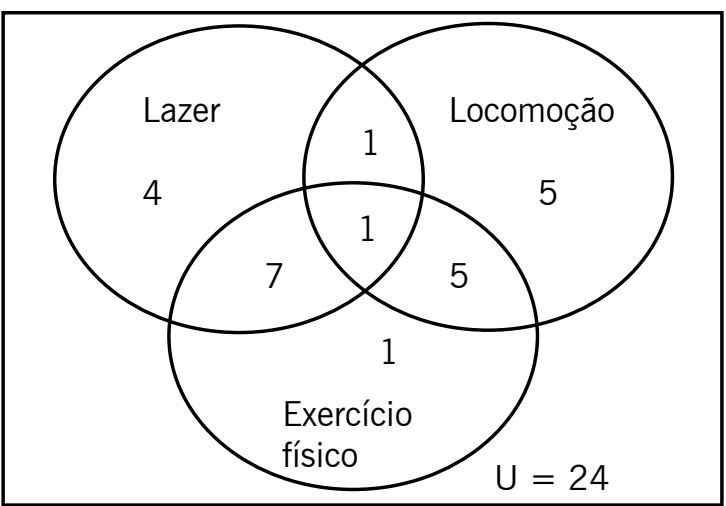

Figura 1 - Conjunto dos informantes de acordo com a finalidade do uso do Bike PE

Fonte: Elaborada pelos autores.

A distinção da utilidade das bicicletas foi importante na medida em que as diferenças nos discursos foram notadas quando constatadas as diferentes finalidades de acesso ao projeto. Estas narrativas foram desenvolvidas a partir da conversação, sendo suas análises abordadas a seguir. Tais análises estão divididas em: (1) questões identitárias ligadas às crenças e aos valores; (2) benefícios e problemas percebidos na prática colaborativa; (3) questões de identidade diante das tecnologias; (4) questões de posse versus acesso; e (5) a extensão do self no consumo colaborativo.

Consumo colaborativo: identidade, crenças e valores

A perspectiva de consumo colaborativo enquanto forma de atender necessidades e desejos com pouco ônus, prezando por atividades sustentáveis e atraentes (Botsman \& Rogers, 2011), além da percepção do autoconceito como um elemento multidimensional, no qual o self social influencia a construção do senso de identidade (Andersen \& Chen, 2002), foi percebida nos relatos dos informantes 1 e 5 :

O compartilhamento é ótimo porque ele não é o compartilhamento em si, mas ele também gera assunto. Ah, se você anda, então já conversa sobre isso. Não é só o compartilhamento por compartilhamento, é também o discurso, você vai falar sobre ele, você vai se amostrar, "ah, eu ando, eu sei como funciona". (I1 - lazer, 2015)

Eu acho que como eu geralmente ando em grupo, eu acho divertido, é uma forma de estar se divertindo em grupo, conhecendo alguns lugares, porque eu geralmente vou pra pontos turísticos e é isso. (15 - lazer, 2015)

De fato, o consumo colaborativo exerce um papel facilitador no processo de conexão e comunicação entre indivíduos (Barnes \& Mattsson, 2017), representando a possibilidade de reafirmar elementos de suas identidades ligados à necessidade de se sentir pertencente a um grupo (self relacional de Andersen e Chen, 2002). Cria-se, portanto, por meio desta prática, um sentimento de identidade grupal que integra o self, tendo em vista que a partir do outro os indivíduos se reconhecem (Belk, 2013). Nessa perspectiva, é realçada a importância dos sentimentos de pertencimento, associação e familiaridade para a adoção e permanência de certas práticas de consumo, especialmente aquelas ligadas ao compartilhamento, corroborando com a compreensão de que tais práticas aumentam o senso de comunidade e auxiliam no processo identitário coletivo que agrega o senso do Eu (Andersen \& Chen, 2002; Markos et al., 2018). Por meio dessa forma de consumo, portanto, indivíduos buscam estabelecer conexões com o mundo e com os outros, diminuindo a insegurança 
em serem vistos como marginalizados ou desconhecedores do novo, corroborando a compreensão de Petrini et al. (2017) de que esta forma de consumo orienta uma ação coletiva.

Junto a esse aspecto de sociabilidade, o sentimento de utilização da bicicleta envolve um elemento emocional que relaciona os selves dos usuários com aspectos de luta por uma causa, destacando o poder do objeto como instrumento de liberdade para a mudança de vida das pessoas e da sociedade em geral, além de gerar uma percepção de influência social exercida pelos informantes ao utilizarem o Bike PE. É o que revelam os usuários 4 e 9:

Eu geralmente tento mostrar a todo mundo que tá ao meu redor que bicicleta pra mim é um instrumento de mudança na minha vida. Então, se eu for sua amiga, você um dia vai andar de bicicleta comigo. Às vezes eu sou até meio que chata, "vamos tentar, vamos tentar", mas a pessoa sempre vai e sempre gosta. (14 - lazer, 2015)

Eu vou formando adeptos . . . eu sempre influencio as pessoas. (I9 - locomoção, 2015)

Dois aspectos iniciais, portanto, emergem dos discursos dos informantes relacionados à construção ou ao reforço dos seus se/ves: a importância do outro para a prática do pedalar utilizando as bicicletas do Bike $\mathrm{PE}$, especialmente quando esta atividade é realizada a lazer, e o comportamento relacionado à capacidade de influência do indivíduo e da sociedade. Tem-se, assim, no primeiro elemento, o self relacional e, no segundo, o self descrito como influenciador e idealista, ambos desenvolvidos a partir do Bike PE e do próprio ato de andar de bicicleta, que transmitem determinadas imagens e significados, ativando benefícios similares nas pessoas (Chaplin \& John, 2005).

A identidade estendida dos usuários também é construída a partir do Bike PE. Os usuários apontam que, por meio do uso das bicicletas compartilhadas, ocorreram mudanças de consciência, em termos políticos, ideológicos, ambientais, sociais e culturais em suas vidas. Tais mudanças são motivadas por determinados valores já possuídos, segundo o discurso dos próprios informantes, como respeito ao próximo, e por outros adquiridos ao longo do uso da bicicleta, como aqueles ecológicos (Martin \& Upham, 2016), de reconhecimento e pertencimento à cultura da cidade e de coletividade, reafirmando a interação que o consumo colaborativo oferece às pessoas (Lang \& Armstrong, 2018), estabelecendo novos valores e sensibilidades (Barnes \& Mattsson, 2017) por meio do acesso e dos sentimentos de coletividade gerados com este. Assim, o consumo compartilhado fez emergir a conscientização sobre cidadania e coletivismo. A partir do Bike PE, os indivíduos passaram a reconhecer que juntos possuem maior poder para exigir seus direitos, sendo agentes de mudança na sociedade. Também se perceberam participantes de um propósito maior, suprindo a necessidade de pertencimento presente no self e, ao mesmo tempo, reconhecendo a importância do outro nas práticas cotidianas de sua vida. As narrativas abaixo reforçam este aspecto.

Eu acho que a coisa mais importante é o respeito aonde a gente tá, com tudo que tá ao nosso redor, pessoas, natureza, tradições também eu acho que precisam ser respeitadas. Mas é realmente isso, de conseguir conviver com harmonia com coisas que você concorda e que você discorda, que haja diálogo entre o que você é ou o que você quer versus o que outras pessoas querem. Que você não tente atropelar tudo que tá pela sua frente que não Ihe agrada. Eu sempre levo as relações humanas, naturais com respeito a quem está do outro lado. (I6 - lazer, 2015)

E quando você tá de bicicleta, você tem toda a liberdade de parar, de tirar a bicicleta da ciclofaixa, se houver ciclofaixa, que é um dos problemas de Recife também, e ir pra aquele lugar. . . É um exercício que me proporcionou viver a cidade. . . Pra mim cada passeio de bike é uma experiência. (17 - lazer, 2015) 
Sempre é válido você oferecer ao usuário um uso compartilhado, isso inclusive também, penso eu, estimula a consciência de coletivo. . . . Ele estimula o pensamento coletivo de que eu vou preservar esse bem, porque outra pessoa vai usar/eu também talvez use no futuro, preservar as estações também. (I18 - locomoção e ex. físico, 2015)

Assim, a bicicleta é entendida como um instrumento que possibilita a criação e exercício de uma consciência política. Por meio dela, os indivíduos reafirmam e lutam por seus direitos de mobilidade, de viver a cidade, de ter uma estrutura adequada para o ato de pedalar, além de reforçar a coletividade. A bicicleta em si estende essa identidade ao auxiliar os informantes a aprender, definir e lembrar a si mesmos de quem são, sendo representativos, segundo Dodson (1996), de suas crenças e atitudes. O projeto Bike PE desenvolve um papel importante na medida em que oferece aos indivíduos a possibilidade de vivenciar tais conscientizações sem a necessidade de possuir o bem, a bicicleta (Zamani et al., 2017), caracterizando-se como consumo circunstancial e temporal (Bardhi \& Eckhardt, 2012; Lang \& Armstrong, 2018).

Consumo colaborativo: benefícios e problemas percebidos

O Bike PE foi descrito pelos informantes como um projeto que auxilia na mudança de mentalidade e na melhoria da qualidade de vida, uma vez que proporciona benefícios à saúde física e financeira. A saúde física foi relatada principalmente por usuários que têm como motivação primária a necessidade de locomoção. "É algo inovador, algo que pode mudar muito a qualidade de vida, não só com relação à mobilidade, mas também com relação à saúde da população" (I20 - locomoção, 2015).

Além de agir como meio de conscientização em termos de sustentabilidade e saúde (Gansky, 2010), o projeto Bike PE apresenta uma nova configuração de consumo que incorpora diferentes vantagens, entre as quais a econômica (Toni, Renzi, \& Mattia, 2018).

Pra mim hoje é mais fácil usar o Bike PE, porque eu não tenho onde guardar, ter manutenção, é menos responsabilidade. Pra mim é mais conveniente o Bike PE. (I2 - lazer, 2015)

Tem vários aspectos assim. 0 primeiro de todos é a questão financeira, porque assim eu fui calcular e eu utilizando a bike e eu percebo que assim é muito em conta. E tem também, aí eu penso por esse lado, mas também tem a questão da saúde assim . . . aí é uma forma também de meu corpo tá em movimento assim, tá pedalando pra saúde mesmo assim. (I3 - locomoção, ex. físico e lazer, 2015)

É a questão da comodidade, de eu poder, eu não precisar me preocupar com a minha. Às vezes eu não tenho um cadeado em casa fácil. Essa comodidade de ter várias estações, vários cantos . . . Então é mais fácil eu usar a do governo que eu não tenho a responsabilidade. (I22 - locomoção, 2015)

Mais barato do que ir pra academia também (E uma coisa ao ar livre né.). É bem melhor e eu moro num apartamento muito pequeno aí pra comprar bicicleta pra guardar, não dá. (I23 - saúde, 2015)

Como observado, além do ganho de ordem econômica em função do baixo custo de acesso ao sistema, o projeto proporciona economia aos usuários em função de não haver responsabilidade pela manutenção da bicicleta, além da comodidade de acesso e adequação às consequências da reurbanização (Bardhi \& Eckhardt, 2012), bem como a rapidez e a adaptabilidade que o uso da bicicleta proporciona, principalmente para aqueles usuários que utilizam o projeto com maior frequência, geralmente com o 
objetivo de locomoção. Essas possibilidades revelam, de acordo com Benoit et al. (2017), um perfil de consumidor em busca de práticas que envolvam ou possibilitem menos obrigações e incumbências.

As narrativas expostas reforçam o argumento de que o consumo colaborativo tem como elementos motivadores a sobrecarga econômica dos indivíduos e a crise financeira global (Dreyer, Lüdeke-Freund, Hamann, \& Faccer, 2017). Ao facilitar o acesso de indivíduos a bens e serviços com menor custo, esse consumo facilita o desenvolvimento do autoconceito (Markos et al., 2018), por meio de produtos que estão relacionados ao self ideal. No entanto, como observado a partir dos discursos dos informantes, deve-se frisar que não é apenas por motivações financeiras que essa prática é realizada (Cheshire et al., 2010). A possibilidade de acesso à bicicleta reduz responsabilidades e possibilita interações e senso de comunidade, que justificam sua adesão.

O Bike PE, no entanto, apresenta alguns problemas observados pelos usuários, tais como: falta de estações suficientes ou de vagas disponíveis nestas para retirada ou devolução das bicicletas, falhas no aplicativo/sistema, bicicletas defeituosas, plataformas em mau-estado de conservação e a falta de infraestrutura para a movimentação com bicicleta pelas vias da cidade do Recife. Durante o período de observação, inclusive, foi possível presenciar tais problemas. Por exemplo, alguns usuários não conseguiam retirar as bicicletas por problemas no leitor e no sistema, que não reconheciam o cartão, e pela indisponibilidade de bicicletas, o que chegava a bloquear o acesso dos usuários. Ademais, bicicletas com falta de manutenção ou quebradas foram identificadas pelos observados no momento de retirada, especialmente por aqueles que buscavam utilizá-las com o objetivo de locomoção.

Tais problemas inclusive comprometem dois dos princípios centrais descritos por Botsman e Rogers (2011) para o funcionamento do consumo colaborativo: a massa crítica e a confiança. A massa crítica no Bike $\mathrm{PE}$, por exemplo, diz respeito à quantidade de bicicletas e estações ofertadas em número suficiente para fazer os indivíduos aderirem ao projeto. No entanto, como descrito anteriormente, as estações e a quantidade de vagas disponíveis em cada uma delas se mostram insuficientes em determinados momentos, dificultando a atração e a escolha pela prática de compartilhamento, além de atrapalhar etapas que antecedem ou sucedem o uso da bicicleta, prejudicando o funcionamento do sistema (Scaraboto, 2015). Devido a esse problema e aos outros citados, a confiança do usuário diminui, comprometendo o gerenciamento do relacionamento entre pessoa-objeto e pessoa-pessoa em meio à menor liberdade que o próprio acesso possibilita na escolha do momento a se utilizar o bem, da duração do uso e de quem pode usufruir desse (Lamberton, 2016; Möhlmann, 2015; Silva \& Barbosa, 2018).

Para que a utilização desta prática colaborativa seja efetiva e influencie os indivíduos a utilizarem a bicicleta mais ativamente, é necessário que o projeto melhore e ofereça acesso rápido, um sistema que facilite o uso e não o dificulte, além de bicicletas e estações suficientes e em bom estado. Os problemas desestimulam o acesso (Lamberton, 2016) - entendido, neste contexto, como a prática do pedalar a partir da experiência do uso possibilitada pelo Bike PE -, fazendo com que o consumo colaborativo, descrito como meio atraente de atender as necessidades dos consumidores (Botsman \& Rogers, 2011), não seja tão estimulante no caso do Bike PE quando se observam os problemas vivenciados.

Deve-se considerar que, apesar dos problemas supracitados, o sistema de compartilhamento de bicicletas se mostrou uma oportunidade para o indivíduo desfrutar de um bem sem necessitar adquiri-lo, dando-Ihe mais opções em termos de configurações de consumo a serem praticadas (Leismann et al., 2013). Mais do que isso, o Bike PE, por meio da bicicleta e do pedalar, foi entendido como um meio de o consumidor socializar e refletir sobre elementos de coletivismo e cidadania. Tal atividade parece gerar uma maior consciência do espaço do outro, do respeito ao pedestre e aos outros motoristas, além de incentivar o pensamento crítico perante as dificuldades enfrentadas no trânsito das cidades. 
Consumo colaborativo: identidade e tecnologia

As tecnologias desempenham um papel essencial no desenvolvimento e consolidação do consumo colaborativo. No caso do Bike PE, elas auxiliam na extensão do self por possibilitarem a experiência (Kunchamboo et al., 2017) do uso da bicicleta. Os usuários só podem acessar a plataforma, retirar, utilizar e devolver a bicicleta graças a um sistema tecnológico e seus aparelhos que possibilitam a conectividade entre todas essas ações. As tecnologias, portanto, desempenham papéis e, neste tipo de consumo, também contribuem para gerar novas mentalidades e novos comportamentos sociais, econômicos e culturais (Santoso \& Erdaka, 2015; Silva \& Barbosa, 2016).

Foi percebido também que as tecnologias, mais especificamente a internet e as redes sociais, possibilitaram mais do que nunca (Belk, 2013) a amplitude de exposição das inúmeras dimensões das identidades dos informantes e a capacidade de transformação delas (Ahuvia, 2005; Sirgy, 1982), tais como os se/ves social, real e ideal, compreendendo, no contexto, a construção do autoconceito a partir de uma perspectiva multidimensional (Razmus et al., 2017). De fato, o que fica mais evidente a partir da descrição da identidade no discurso dos entrevistados é a sua multiplicidade de características (Morgan, 1993), reafirmando a necessidade de observá-la a partir da compreensão múltipla e de possible selves (Hanley et al., 2018), como apontam os seguintes informantes:

É tudo muito global. Eu me sinto muito próxima das coisas que eu acredito, porque eu consigo participar virtualmente dessas coisas. (I4 - Lazer, 2015)

Eu acho que as pessoas vivem em dois mundos diferentes. Um mundo que ela deseja demonstrar, que é o mundo virtual, e o mundo que ela tá de verdade. Não sei, eu tenho uma impressão de que muitas vezes o facebook, o instagram, essas coisas é muito um mundo de ilusão assim (De aparências?). É, mais o que você quer ser do que o que você é. (I6 - lazer, 2015)

Vantagens [das tecnologias] é acessibilidade, você faz tudo com mais rapidez, tudinho, além de ser o que quiser. (I10 - lazer, 2015)

As tecnologias possibilitam a aproximação de grupos, pessoas com ideias similares, reforçando a acessibilidade ofertada a partir delas (Baumhammer et al., 2017). Ao mesmo tempo, no mundo virtual os indivíduos têm necessidade de status e de reconhecimento, estando dispostos a moldar e construir seus selves para tal atividade. A vida virtual, portanto, é compreendida como um ambiente de aparências, em que os internautas podem melhorar suas histórias a fim de receber mais comentários e curtidas, sentindo-se compartilhadores da mesma felicidade dos demais e capazes de ter características comportamentais diferentes das presenciadas na realidade off-line. Tal possibilidade reflete a diferença entre o ser real e o ser construído virtualmente. Este Eu despido no mundo virtual representa, então, a exposição de um self desejado em detrimento do self real (Belk, 2014a; Schau \& Gilly, 2003), motivado pela necessidade de expor a felicidade tão buscada na sociedade atual.

É justamente nesta exposição do self que os usuários do projeto demonstram suas experiências com as bicicletas do Bike PE. Muitos que acessam tais bens, principalmente com finalidade de lazer, registram tais momentos por meio de fotos e vídeos, compartilhando em suas redes sociais os momentos vivenciados. O informante 15, por exemplo, divulgou seu vídeo do primeiro contato com o Bike PE, conforme seu depoimento: "Eu estava muito eufórico aí [risos durante todo o vídeo]. Eu mandei pros meus irmãos [vídeo acaba]. Pronto, essa foi minha primeira experiência, realmente eu estava muito eufórico aí [risos]. Depois postei no face" (I15 - locomoção e ex. físico, 2015). 
As redes sociais contribuem para a divulgação do sistema e para o uso das bicicletas compartilhadas, especialmente por possibilitarem a recordação e o arquivamento dessas experiências por meio de memórias distribuídas na rede, que reforçam o senso do Eu por meio do passado (Belk, 2013). Os usuários do projeto retratam experiências positivas, como a apontada acima, mas também expõem os problemas que vivenciam ao tentar acessar o Bike PE. O mais importante é poder discursar sobre o compartilhamento (Hartl et al., 2016), expor experiências, mostrando a adesão ao projeto e conhecimento do seu funcionamento, gerando conexão e comunicação entre indivíduos e grupos de interesse (Lamberton, 2016).

\title{
Consumo colaborativo: posse versus acesso?
}

Apesar dos aspectos anteriormente apresentados se mostrarem relevantes para melhor compreensão deste tipo de consumo colaborativo, não se percebeu nas narrativas dos participantes um processo de desmaterialização, como preconizam Lang e Armstrong (2018). Esse entendimento é representado pelas narrativas expostas abaixo:

\begin{abstract}
Eu tenho bicicleta, mas alguns amigos não, e como tem o espaço de algum tempo pra usar, eu achava chato eu ir com a minha e eles ficarem lá esperando o projeto. Aí quando eu vou sair com eles, eu sempre uso as bicicletas do projeto. (I5 - lazer, 2015)
\end{abstract}

Na verdade eu tenho três [risos]. Aí às vezes não dá pra usar, levar a bicicleta, enfim, por algum motivo, aí eu prefiro usar a do Itaú. Na verdade, prefiro não, prefiro não usar a do Itaú, porque a manutenção é horrível. (I6 - lazer, 2015)

(E tua frequência de uso?) Bem, pelo menos uma a duas vezes na semana, porque assim, eu tenho bicicleta também e eu moro aqui perto. Aí nem sempre eu preciso pegar, às vezes por causa de tempo também. Mas eu acho que uma a duas vezes por semana. (I16 - locomoção, 2015)

A partir das falas dos respondentes foi possível compreender como os usuários estendem e constroem suas identidades por meio do compartilhamento de bicicletas; entretanto, não se pode afirmar que há uma mudança do "eu sou o que possuo" (Belk, 1988) para o "eu sou o que eu posso acessar" (Belk, 2014b), uma vez que a possibilidade de acesso à bicicleta não diminui o desejo de possuí-la para alguns entrevistados, contrariando a perspectiva de que a prática colaborativa vai de encontro à possessividade (Markus \& Orsi, 2016).

Pode-se até dizer que o compartilhamento contribuiu para estimular a aquisição da bicicleta em alguns casos, devido ao prazer gerado pela experiência de pedalar aliado aos problemas no uso do sistema e das bicicletas enfrentados pelos informantes, causando mais impacto naqueles que utilizam o sistema com fins de locomoção. Entre os principais problemas relatados e que ocorrem com maior frequência, destacam-se: problemas no sistema, na retirada e na devolução das bicicletas, falta de plataformas e espaços para a devolução das bicicletas e a existência de bicicletas danificadas.

Diante dessas circunstâncias é plausível admitir que as situações adversas enfrentadas pelos usuários desestimulam o uso do sistema e, portanto, o acesso não possui vantagens suficientes para substituir completamente a posse. 0 que se pôde perceber é que acesso e propriedade coexistem em alguns casos, na medida em que ambos apresentam benefícios para os consumidores. Tal afirmação reforça a ideia de que as práticas colaborativas não buscam criticar diretamente o capitalismo, nem extinguir a condição de possuir (Barnes \& Mattsson, 2017), mas se constituem como formas distintas e alternativas de atender necessidades, apresentando diferenças e vantagens que não podem ser oferecidas por meio da posse, sendo possível e necessária a coexistência das duas formas de consumo (tradicional e colaborativo). 0 acesso, de acordo com Zamani et al. (2017), 
oferece uma direção diferente do consumo dominante, mas não o impede ou o intimida. Não se percebeu, portanto, a partir dos relatos, um apelo forte do princípio de desmaterialização para a maioria dos usuários entrevistados (Lang \& Armstrong, 2018).

Ademais, a aquisição de uma bicicleta não representa para os usuários do projeto uma ação de individualismo, mas, sim, uma compra realizada por motivo de preocupação com a coletividade, devido à consciência política e ideológica adquirida durante o acesso ao Bike PE. A bicicleta é entendida como elemento de transformação coletiva, que também se apresenta como uma extensão do Eu quando possuída.

Rapaz, foi um processo curto e intenso, na verdade. Porque eu voltei a andar de bicicleta no final de dezembro [com a bicicleta do projeto], final de 2014 em dezembro, e não tinha noção do que a bicicleta significaria na minha vida, é verdade. É uma relação muito intensa, é praticamente como se fosse minhas pernas hoje. Então ela é muito responsável pela minha liberdade. Eu atribuo ela à minha liberdade e eu sinto prazer demais em usar, me deslocar usando ela, porque eu me sinto contribuindo pra tudo. (I6 - lazer, 2015)

Como descrito pelo informante 6 , tanto as bicicletas que possui como as acessadas no Bike PE são partes do seu corpo e de sua identidade, sendo importantes na construção e extensão de seu self. Mais do que o desejo de tê-las, tem-se o desejo de ser unido a elas numa relação íntima (Roux \& Korchia, 2006), transpassando o seu eu para as bicicletas, independentemente de serem próprias ou não. Portanto, parece que a cultura e psicologia da propriedade, diferentemente de como descreve Gansky (2010), não se encontram em total transição quando o projeto de compartilhamento de bicicletas de Pernambuco é observado.

A extensão do self no consumo colaborativo

A pesquisa visou compreender a extensão da identidade dos usuários do Bike PE na prática colaborativa de compartilhamento de bicicletas, desenvolvendo uma reflexão acerca da relação entre posse e acesso. Esta seção tem como finalidade responder a esse objetivo a partir das análises realizadas nas seções anteriores. Surge, portanto, como um tópico para responder o problema de pesquisa a partir dos resultados obtidos.

A ideia de extensão do Eu refere-se às posses que os indivíduos consideram como parte de si mesmos, ultrapassando e externando suas identidades por meio delas (Ahuvia, 2005; Belk, 1988; Gjersoe et al., 2014). Atualmente, entretanto, é possível que as pessoas externem seus se/ves por meio de outras práticas que não envolvem a propriedade de um bem, mas o acesso a ele.

De acordo com as narrativas sobre vivência, identidade, valores e crenças, os informantes demonstraram a extensão de seus selves na experiência de compartilhamento por meio do significado do uso do objeto disponibilizado, no caso, a bicicleta. A possibilidade de pedalar a partir do projeto Bike PE, independentemente da finalidade do uso, representa a possibilidade de reafirmar e construir certos elementos identitários ligados especialmente ao self social (Lang \& Armstrong, 2018). Ainda que a posse de uma ou mais bicicletas possa contribuir para externar tal característica identitária, é por meio da participação como integrante do projeto e do uso da bicicleta que se estimula o aumento do senso de comunidade, criando sentimentos de identidade grupal que agregam ao senso do Eu (Andersen \& Chen, 2002; Markos et al., 2018). Reitera-se, a partir da participação no Bike PE, a busca por uma identidade construída em conjunto, interativa e manifestada em atividades colaborativas, criando conexões entre indivíduo e coletivo e estimulando ações conjuntas (Petrini et al., 2017).

Essa coconstrução do self é estabelecida a partir do engajamento entre usuários e conhecedores do projeto que expõem suas experiências e as (res)significam a partir das interações, algumas delas ocorridas em redes sociais. Por isso, mais do que participar de práticas de compartilhamento, os usuários sentem 
necessidade de discursar sobre elas (Hartl et al., 2016). Ao assim fazer, exibem um self influenciador e multiplamente manifestado, que orienta vivências e decisões de consumo, e um self também influenciado pelas experiências e comentários dos outros, que realça o contexto da colaboração.

A identidade estendida por meio do uso é construída também pelo significado do objeto utilizado (Möhlmann, 2015). A bicicleta, seja compartilhada ou própria, gera vínculos afetivos com aquele que dela usufrui e representa, para os informantes, uma nova forma de viver, possibilitando o exercício da cidadania, acrescentando valores e crenças pautadas nos direitos de mobilidade, promovendo mudança, seja esta política, ideológica, ambiental ou ligada à saúde, externando um self idealista. Portanto, a extensão desse self a partir da bicicleta se dá em práticas colaborativas, como no projeto de compartilhamento analisado, mas também em práticas tradicionais, em que existe a propriedade desse bem. O Bike PE, no entanto, auxiliou na construção do Eu idealista que, posteriormente, foi externado a partir do pedalar, gerando, inclusive, o desejo de possuir uma bicicleta.

Assim, não é possível afirmar que o acesso extingue a posse e vice-versa. Ambos são realizados e cada um oferece a possibilidade de extensão e construção do self de maneiras diferentes, ou até mesmo iguais, pois, como lembra Belk (2014a), talvez os indivíduos que possuam determinados objetos estejam ligados ao seu uso e sua possibilidade de ajuda mais do que à posse em si. De modo especial, no Bike PE tais possibilidades emergem a partir de motivações tão altruístas como egoístas.

Reforça-se, assim, que os consumidores podem ser aquilo que possuem, mas também aquilo que acessam. De maneira mais integrativa, ao repensar a sugestão de Belk (2014a) e ao observar a experiência do Bike PE, em que os indivíduos expõem e constroem seus selves a partir do significado do uso da bicicleta, da experiência possibilitada pelo acesso, pode-se supor que os indivíduos são o que usam, ou melhor, o que consomem, independentemente de serem proprietários ou não do produto consumido. Eis um elemento que se mostrou central na fala dos informantes: o consumo. Para além da configuração (consumo mais tradicional, partilha, consumo colaborativo) e da frequência (alguns informantes se descrevem como mais consumistas, enquanto outros revelam consumir o mínimo possível), tal atividade foi vista como fundamental na vida dos indivíduos, auxiliando-os a construir noções de si (Ruvio \& Belk, 2018), dando margem para a compreensão de que as pessoas são o que consomem, o que experienciam (Silva \& Barbosa, 2018).

\section{Considerações finais}

Muito se fala sobre a alternativa de viver sem adquirir bens, tendo no compartilhamento a atividade para o alcance desta realidade. Entretanto, ao colocar acesso e propriedade em lados opostos, a complementariedade de ambos se esvai, impossibilitando uma reflexão profunda orientada à compreensão de cada um destes fenômenos e seus impactos no dia a dia dos indivíduos na atualidade. Nesse sentido, o presente estudo buscou observar nos discursos dos informantes as relações entre propriedade e acesso, não assumindo uma atividade como mais valorosa ou de melhor escolha do que a outra.

Ressalta-se a importância da realização desta pesquisa a partir da experiência de uma prática colaborativa que tem obtido êxito nas cidades de Recife, Jaboatão dos Guararapes e Olinda, o que pode revelar que o consumidor está disposto a experimentar novos modelos de prestação de serviços, não significando, porém, um abandono completo das antigas práticas de consumo, como a aquisição. Esses indivíduos identificam, tanto no acesso quanto na posse, uma possibilidade de aumentar a extensão e construção do self, que são o reflexo de identidades multifacetadas.

De modo específico, a extensão e construção do Eu no tipo de consumo colaborativo analisado revelou a importância do significado do uso para a identidade dos clientes. Tal afirmativa gerou a reflexão sobre a relevância da funcionalidade do bem para o self do consumidor, independentemente de a atividade resultar no acesso ou na propriedade. 0 que se quer dizer com esta assertiva é que talvez o uso e o seu significado 
representem também uma forma de os indivíduos se estenderem às suas posses. O bem possuído, da mesma forma que o acesso, adquire sentido quando utilizado, possibilitando ao consumidor expor e edificar sua identidade a partir da experiência do uso.

A ideia de experiência contribui com a visão de que o significado do uso é importante para os estudos do comportamento do consumidor, pois experimentar implica testar, usufruir e vivenciar aquele momento a partir dos objetos e pessoas que o possibilitam. A utilização tem, portanto, destaque como fonte de experiências para os consumidores, seja o objeto usado próprio ou não. A diversidade em construir e estender 0 self por meio do consumo se apresenta como uma possibilidade para as empresas desenvolverem estratégias voltadas à oferta de bens e serviços compartilhados, atendendo ao indivíduo ansioso por interação que busca os benefícios do acesso, entre os quais a pequena quantia cobrada para o consumo.

Apesar de o estudo ampliar a compreensão do consumo colaborativo e as possibilidades de construção e extensão do self, considera-se como fator limitante a utilização de apenas um lócus de pesquisa, no caso o Bike PE, que, conforme exposto por Botsman e Rogers (2011), representa um dos três grupos de consumo colaborativo, no caso, o SSP. Oportunidades para futuras pesquisas podem ser geradas a partir desta experiência inicial.

No campo acadêmico, o consumo colaborativo pode estimular pesquisas que visem analisá-lo por meio de outras práticas, atentando para as diferenças destas em relação ao consumo tradicional. Aliás, como sugestão para pesquisas futuras, outros elementos estudados no comportamento do consumidor podem ser analisados tendo como lócus de pesquisa práticas do consumo colaborativo como, por exemplo, processos decisórios, construção de atitudes e comportamentos, desenvolvimento de emoções e grupos de referência. Destaca-se, ainda, a possibilidade de estudos que busquem observar a relação dos indivíduos com a bicicleta, seja ela própria ou compartilhada, tendo em vista o caráter de mudança a partir dela sofrido pelos informantes desta pesquisa.

\section{Referências}

Ahuvia, A. C. (2005). Beyond the extended self: Loved objects and consumers' identity narratives. Journal of Consumer Research, 32(1), 171-184. doi:10.1086/429607

Algar, R. (2007, abril). Collaborative consumption. Leisure Report, 16-17. Recuperado de http://bit.ly/37YvPjS

Andersen, S. M., \& Chen, S. (2002). The relational self: An interpersonal social-cognitive theory. Psychological Review, 109(4), 619-645. doi:10.1037/0033-295X.109.4.619

Bagozzi, R. P. (2013). Social influence and the self. In A. Ruvio, \& R. Belk, (Orgs.), The Routledge companion to identity and consumption (pp. 255-264). London: Routledge.

Bardhi, F., \& Eckhardt, G. (2012). Access-based consumption: The case of car sharing. Journal of Consumer Research, 39(4), 881-898. doi:10.1086/666376

Barnes, S. J., \& Mattsson, J. (2017). Understanding collaborative consumption: Test of a theoretical model. Technological Forecasting and Social Change, 118, 281-292. doi:10.1016/j.techfore.2017.02.029

Baumhammer, P., Silva, M. G., \& Costa, M. F. (2017). Aspectos simbólicos do smartphone e o eu estendido: Um estudo do comportamento do consumidor português. Revista Interdisciplinar de Marketing, 7(2), 175-190. doi:10.4025/rimar.v7i2.34904

Belk, R. W. (1988). Possessions and the extended self. Journal of Consumer Research, 15(2), 139-168. doi:10.1086/209154 
Belk, R. W. (2013). Extended self in a digital world. Journal of Consumer Research, 40(3), 477-500. doi: $10.1086 / 671052$

Belk, R. W. (2014a). Digital consumption and the extended self. Journal of Marketing Management, 30(1112), 1101-1118. doi:10.1080/0267257X.2014.939217

Belk, R. W. (2014b). You are what you can access: Sharing and collaborative consumption online. Journal of Business Research, 67(8), 1595-1600. doi:10.1016/j.jbusres.2013.10.001

Benoit, S., Baker, T. L., Bolton, R. N., Gruber, T., \& Kandampully, J. (2017). A triadic framework for collaborative consumption (CC): Motives, activities and resources \& capabilities of actors. Journal of Business Research, 79, 219-227. doi:10.1016/j.jbusres.2017.05.004

Bike PE. (2017). Bike PE Pernambuco. Recuperado de http://bit.ly/2HXM5Hm

Bike PE. (2018). Funcionamento. In Bike PE Pernambuco. Recuperado de http://bit.ly/2TfFXPP

Botsman, R., \& Rogers, R. (2011). O que é meu é seu: Como o consumo colaborativo vai mudar o nosso mundo. Porto Alegre, RS: Bookman.

Caelli, K., Ray, L., \& Mill, J. (2003). "Clear as mud": Toward greater clarity in generic qualitative research. International Journal of Qualitative Methods, 2(2), 1-13. doi:10.1177/160940690300200201

Chaplin, L. N., \& John, D. R. (2005). The development of self-brand connections in children and adolescents. Journal of Consumer Research, 32(1), 119-129. doi:10.1086/426622

Cheshire, L., Walters, P., \& Rosenblatt, T. (2010). The politics of housing consumption: Renters as flawed consumers on a master planned estate. Urban Studies, 47(12), 25972614. doi: $10.1177 / 0042098009359028$

Correa, J., Garzón, W., Brooker, P., Sakarkar, G., Carranza, S. A., Yunado, L., \& Rincón, A. (2019). Evaluation of collaborative consumption of food delivery services through web mining techniques. Journal of Retailing and Consumer Services, 46, 45-50.

Dodson, K. (1996). Peak experiences and mountain biking: Incorporating the bike into the extended self. Advances in Consumer Research, 23, 317-322.

Dolich, I. J. (1969). Congruence relationship between self images and product brands. Journal of Marketing Research, 6(1), 80-84. doi:10.2307/3150001

Dreyer, B., Lüdeke-Freund, F., Hamann, R., \& Faccer, K. (2017). Upsides and downsides of the sharing economy: Collaborative consumption business models' stakeholder value impacts and their relationship to context. Technological Forecasting and Social Change, 125, 87-104. doi:10.1016/j. techfore.2017.03.036

Felson, M., \& Spaeth, J. (1978). Community structure and collaborative consumption. American Behavioral Scientist, 21(4), 614-624. doi:10.1177/000276427802100411

Flick, U. (2004). Uma introdução à pesquisa qualitativa. São Paulo, SP: Bookman.

Freitas, C. S., Petrini, M. C., \& Silveira, L. M. (2016). Desvendando o consumo colaborativo: Uma proposta de tipologia. Trabalho apresentado no $9^{\circ}$ Congresso Latino-Americano de Varejo, São Paulo, SP. Recuperado de http://bit.ly/3c39TqS

Gansky, L. (2010). The mesh: Why the future of business is sharing. London: Portfolio.

Gjersoe, N. L., Newman, G. E., Chituc, V., \& Hood, B. (2014). Individualism and the extended-self: Crosscultural differences in the valuation of authentic objects. PLOS ONE, 9(3), e90787. doi:10.1371/ journal.pone.0090787 
Godoi, C. K. (2010). Perspectivas de análise do discurso nos estudos organizacionais. In C. K. Godoi, R. Bandeira-de-Melo, \& A. B. Silva (Orgs.), Pesquisa qualitativa em estudos organizacionais (2a ed., pp. 375-402). São Paulo, SP: Saraiva.

Grubb, E. L., \& Grathwohl, L. H. (1967). Consumer self-concept, symbolism and market behavior: A theoretical approach. Journal of Marketing, 31(4, Pt 1), 22-27. doi:10.2307/1249461

Hamari, J., Sjöklint, M., \& Ukkonen, A. (2016). The sharing economy: Why people participate in collaborative consumption. Journal of the Association for Information Science and Technology, 67(9), 2047-2059. doi:10.1002/asi.23552

Hanley, A. W., Baker, A. K., Hanley, R. T., \& Garland, E. L. (2018). The shape of self-extension: Mapping the extended self with multidimensional scaling. Personality and Individual Differences, 126, 25-32. doi:10.1016/j.paid.2017.12.013

Hartl, B., Hofmann, E., \& Kirchler, E. (2016). Do we need rules for "what's mine is yours"? Governance in collaborative consumption communities. Journal of Business Research, 69(8), 2756-2763. doi:10.1016/j.jbusres.2015.11.011

Kizgin, H., Jamal, A., \& Richard, M.-O. (2018). Consumption of products from heritage and host cultures: The role of acculturation attitudes and behaviors. Journal of Business Research, 82, 320-329. doi:10.1016/j. jbusres.2017.09.011

Kunchamboo, V., Lee, C. K. C., \& Brace-Govan, J. (2017). Nature as extended-self: Sacred nature relationship and implications for responsible consumption behavior. Journal of Business Research, 74, 126-132. doi:10.1016/j.jbusres.2016.10.023

Lamberton, C. (2016). Collaborative consumption: A goal-based framework. Current Opinion in Psychology, 10, 55-59. doi:10.1016/j.copsyc.2015.12.004

Lang, C., \& Armstrong, C. M. J. (2018). Collaborative consumption: The influence of fashion leadership, need for uniqueness, and materialism on female consumers' adoption of clothing renting and swapping. Sustainable Production and Consumption, 13, 37-47. doi:10.1016/j.spc.2017.11.005

Leismann, K., Schmitt, M., Rohn, H., \& Baedeker, C. (2013). Collaborative consumption: Towards a resourcesaving consumption culture. Resources, 2(3), 184-203. doi:10.3390/resources2030184

Levy, S. J. (1959). Symbols for sale. Harvard Business Review, 37(4), 117-124.

Liu, R. L., Sprott, D. E., Spangenberg, E. R., Czellar, S., \& Voss, K. E. (2018). Consumer preference for national vs. private brands: The influence of brand engagement and self-concept threat. Journal of Retailing and Consumer Services, 41, 90-100. doi:10.1016/j.jretconser.2017.11.010

Markos, E., Labrecque, L. I., \& Milne, G. R. (2018). A new information lens: The self-concept and exchange context as a means to understand information sensitivity of anonymous and personal identifying information. Journal of Interactive Marketing, 42, 46-62. doi:10.1016/j.intmar.2018.01.004

Markus, H., \& Nurius, P. (1986). Possible selves. American Psychologist, 41(9), 954-969.

Markus, K., \& Orsi, D. F. O. (2016). Um estudo do consumo colaborativo no Brasil e nos Estados Unidos da América. Organizações em Contexto, 12(24), 117-129. doi:10.15603/1982-8756/roc.v12n24p117-129

Martin, C. J., \& Upham, P. (2016). Grassroots social innovation and the mobilisation of values in collaborative consumption: A conceptual model. Journal of Cleaner Production, 134(Pt A), 204-213. doi:10.1016/j. jclepro.2015.04.062

Mattos, P. L. (2005). A entrevista não-estruturada como forma de conversação: Razões e sugestões para sua análise. Revista de Administração Pública, 39(4), 283-846. Recuperado de http://bit.ly/2T00V6a 
May, T. (2004). Pesquisa social: Questões, métodos e processos. Porto Alegre, RS: Artmed.

Merriam, J. B. (Ed.). (2002). Qualitative research in practice: Examples for discussion and analysis. New York: Jossey-Bass.

Mittal, B. (2015). Self-concept clarity: Exploring its role in consumer behavior. Journal of Economic Psychology, 46, 98-110. doi:10.1016/j.joep.2014.11.003

Möhlmann, M. (2015). Collaborative consumption: Determinants of satisfaction and the likelihood of using a sharing economy option again. Journal of Consumer Behaviour, 14(3), 193-207. doi:10.1002/cb.1512

Morgan, A. J. (1993). The evolving self in consumer behavior: Exploring possible selves. Advances in Consumer Research, 20, 429-432.

Pernambuco implanta programa de compartilhamento de bicicletas. (2013, 25 de março). Recife, PE. Recuperado de http://bit.ly/380NhUH

Petrini, M., Freitas, C. S., \& Silveira, L. M. S. (2017). A proposal for a typology of sharing economy. Revista de Administração Mackenzie, 18(5), 39-62. doi:10.1590/1678-69712017/administracao.v18n5p39-62

Pilarska, A. (2016). How do self-concept differentiation and self-concept clarity interrelate in predicting sense of personal identity? Personality and Individual Differences, 102, 85-89. doi:10.1016/j. paid.2016.06.064

Piscicelli, L., Cooper, T., \& Fisher, T. (2015). The role of values in collaborative consumption: insights from a product-service system for lending and borrowing in the UK. Journal of Cleaner Production, 97, 21-29. doi:10.1016/j.jclepro.2014.07.032

Pullman, M., \& Gross, M. (2003). Welcome to your experience: Where you can check out anytime you'd like, but you can never leave. Journal of Business and Management, 9(3), 215-232.

Razmus, W., Jaroszyńska, M., \& Palęga, M. (2017). Personal aspirations and brand engagement in selfconcept. Personality and Individual Differences, 105(C), 294-299. doi:10.1016/j.paid.2016.10.018

Reed, A., II (2002). Social identity as a useful perspective for self-concept-based consumer research. Psychology \& Marketing, 19(3), 235-266. doi:10.1002/mar.10011

Rifkin, J. (2000). The Age of Access: The new culture of hypercapitalism where all of life is a paid-for experience. New York: J. P. Tarcher/Putnam.

Roux, D., \& Korchia, M. (2006). Am I what I wear? An exploratory study of symbolic meanings associated with second hand clothing. Advances in Consumer Research, 33, 2935.

Ruvio, A., \& Belk, R. (2018). Strategies of the extended self: The role of possessions in transpeople's conflicted selves. Journal of Business Research, 88, 102-110. doi:10.1016/j.jbusres.2018.03.014

Sampieri, R. H., Collado, C. F., \& Lucio, P. B. (2006). Metodologia de pesquisa (3a ed.). São Paulo, SP: McGraw-Hill.

Santoso, A. S., \& Erdaka, A. (2015). Customer loyalty in collaborative consumption model: Empirical study of CRM for product-service system-based e-commerce in Indonesia. Procedia Computer Science, 72, 543-551. doi:10.1016/j.procs.2015.12.162

Scaraboto, D. (2015). Selling, sharing, and everything in between: The hybrid economies of collaborative networks. Journal of Consumer Research, 42(1), 152-176. doi:10.1093/jcr/ucv004

Schau, H. J., \& Gilly, M. C. (2003). We are what we post? Self-presentation in personal web space. Journal of Consumer Research, 30(3), 385-404. doi:10.1086/378616 
Shankar, A., Elliott, R., \& Fitchett, J. A. (2009). Identity, consumption and narratives of socialization. Marketing Theory, 9(1), 75-94. doi:10.1177/1470593108100062

Silva, M. J. B., \& Barbosa, M. L. (2016). Da posse à possibilidade do acesso? Compreendendo os conceitos de consumo colaborativo no marketing. Revista Interdisciplinar de Marketing, 6(2), 42-53. Recuperado de http://bit.ly/3aasiR1

Silva, M. J B., \& Barbosa, M. L. (2018). Compartilhando bicicletas e consumindo experiências: Uma investigação do consumo colaborativo praticado por usuários do Bike PE. Consumer Behavior Review, 2(ed. esp.), 1-18. doi:10.21714/2526-78842018v2specialp1-18

Silverman, D. (Ed.). (2010). Qualitative research: Issues of theory, method and practice (3a ed.). Thousand Oaks: Sage.

Sirgy, M. J. (1982). Self-concept in consumer behavior: A critical review. Journal of Consumer Research, 9(3), 287-300. doi:10.1086/208924

Toni, M., Renzi, M. F., \& Mattia, G. (2018). Understanding the link between collaborative economy and sustainable behaviour: An empirical investigation. Journal of Cleaner Production, 172, 4467-4477. doi:10.1016/j.jclepro.2017.11.110

Vaquero, A. C., \& Calle, P. C. (2013). The collaborative consumption: A form of consumption adapted to modern times. Revista de Estudios Económicos y Empresariales, (25), 15-30. Recuperado de http://bit.ly/2SZpjVK

Vouga, A. (2017). Influências contraculturais no consumo colaborativo: insights no contexto do Couchsurfing. com. Consumer Behavior Review, 1(2), 73-81. doi:10.21714/2526-78842017v1n2p73-81

Zamani, B., Sandin, G., \& Peters, G. M. (2017). Life cycle assessment of clothing libraries: Can collaborative consumption reduce the environmental impact of fast fashion? Journal of Cleaner Production, 162, 13681375. doi:10.1016/j.jclepro.2017.06.128

\section{Agradecimentos}

À Coordenação de Aperfeiçoamento de Pessoal de Nível Superior, com cujo apoio o presente trabalho foi realizado Código de Financiamento 001.

\section{Sobre os Autores}

\section{Marianny Jessica de Brito Silva}

Doutora em administração pela Universidade Federal de Pernambuco (UFPE). Participante do grupo de pesquisa ConsuMeering - Engenharia do Consumidor da UFPE, atuando na área de marketing, principalmente nos temas: consumer culture theory, comportamento do consumidor, consumo colaborativo, sacrifício no consumo, grupos de referência e redes sociais. Realizou período de doutorado sanduíche na Breda University of Applied Sciences. E-mail: marianny.jbrito@gmail.com. ORCID: 0000-0001-5567-3657

\section{Maria de Lourdes de Azevedo Barbosa}

Doutora em administração pela Universidade Federal de Pernambuco (UFPE). Professora do Programa de Pós-Graduação em Hotelaria e Turismo da UFPE. E-mail: lourdesbarbosa@gmail.com. ORCID: 0000-0002-1790-380X 


\section{Marconi Freitas da Costa}

Doutor em administração pela Universidade de São Paulo. Vice-coordenador do Programa de Pós-Graduação em Gestão, Inovação e Consumo da Universidade Federal de Pernambuco e professor permanente do Programa de Pós-Graduação em Administração e do Programa de Pós-Graduação em Hotelaria e Turismo da mesma instituição. Fez estágio doutoral na Universidade de Boston e no Massachusetts Institute of Technology (EUA). E-mail: marconi_costa@hotmail.com. ORCID: 0000-0001-9888-8359

\section{Jairo de Pontes Gomes}

Doutor em administração pela Universidade Federal de Pernambuco. Professor pesquisador do Centro de Ciências Sociais Aplicadas da Universidade Federal da Paraíba. E-mail: jairopontes@yahoo.com. ORCID: 0000-0003-2658-0317 